\title{
STRESS AND DEFORMATIONS IN TOROIDAL SHELLS WITH ELLIPTICAL TRANSVERSAL SECTION
}

\author{
RADU IATAN ${ }^{* 1}$, GHEORGHIŢA TOMESCU ${ }^{1}$, ION DURBACA ${ }^{1}$ \\ ${ }^{1}$ Politehnica University of Bucharest, Spl. Independenţei 313, Bucharest, Romania
}

\begin{abstract}
The article approaches the analysis of stress and deformation states; in the toroidal shell with the elliptical cross section with two specific positions, relative to the axis of symmetry. The internal pressure of a working environment as well as the effect of its temperature are considered external loads. The two effects may overlap taking into account the elastic state of the shell material.
\end{abstract}

Keywords: Stress, deformations, toroidal shells, external loads

\section{INTRODUCTION}

The industrial equipment's in the structure of the process technology, among other forms of shells, also contains toroidal elliptical cross-sections with large semiax along the axis of symmetry or perpendicular to it. These structures are used, as well as those with a circular cross-section, with the advantages recognized in terms of economics of building materials or diminution of the stress concentration by connecting with other geometrical shapes of envelopes [1-14]. In addition to the stable application in the elastic field of application, the literature also considers the elastic or plastic instability of such structures [9-11].

\section{TOROIDAL SHELL WITH ELLIPTICAL TRANSVERSAL SECTION}

\subsection{The main curvature rays}

When replacing with an ellipse the circle which can generate a toroidal surface with large semiax along the $O x$ axis and originated in the center of the ellipse and the small semiax along the $O y$ axis and also originated in the center of the ellipse, the main radii of curvature are form as [15]:

$$
R_{1}=\left[1+(d r / d y)^{2}\right]^{3 / 2} /\left(d^{2} r / d y^{2}\right) ; R_{2}=r /|\sin \varphi|
$$

Note: In order to preserve the physical significances of the calculated sizes (main radii of curvature, stresses and deformations), the following will be accepted $|\sin \varphi|$ although for the contour $\overparen{A B C}$ of the ellipse the value of the function is positive, while for the contour $\overparen{C D A}$ it has a negative value (the portion $\overparen{D A}$ ).

The current radius of an ellipse point is determined by the formula [15]:

\footnotetext{
* Corresponding author, email: iatan.radu@gmail.com

(c) 2019 Alma Mater Publishing House
} 


$$
r=R_{0} \pm \sqrt{a^{2} \cdot\left(1-y^{2} / b^{2}\right)}
$$

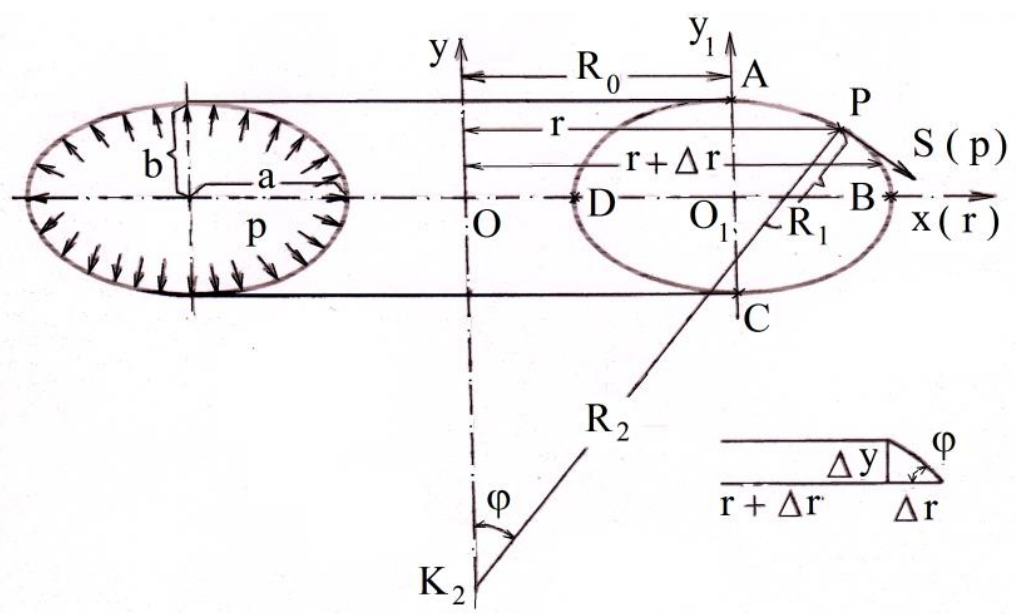

Fig. 1. Toroidal shell with elliptical cross-section with large horizontal axis $(a>b)[15,16]$.

The (+) sign characterizing the semi ellipse $\overparen{A B C}$, and the (-) sign semi ellipse $\overparen{C D A}$. In this way, the current $x$ quota will be accepted with a positive value in the evaluation of the distance between the current radius $r$ and the position of the center of the ellipse defined by $R_{0}$. After crossing the $\operatorname{arc} \widehat{A B}$, the point $P$ on route $\widehat{B C}$ is defined by the existence of the center $K_{2}$, which is above the straight $O O_{1}$ (mirror image). As a result, symmetric $P$ points relative to $O O_{1}$ will be at the same distance $x$, measured with respect to the vertical axis $O_{1} y_{1}$. A similar position can be specified for the current $P$ points, which pass the route $\overparen{C D A}$. The following observations can be made [15]:

\section{- for contour $\overparen{A B C}$ :}

$$
\begin{gathered}
d r / d y=-\left[a \cdot \sqrt{a^{2}-\left(r-R_{0}\right)^{2}}\right] /\left[b \cdot\left(r-R_{0}\right)\right] \\
d^{2} r / d y^{2}=-a^{4} /\left[b^{2} \cdot\left(r-R_{0}\right)^{3}\right]
\end{gathered}
$$

\section{- for contour $\overparen{C D A}$ :}

$$
\begin{gathered}
d r / d y=\left[a \cdot \sqrt{a^{2}-\left(R_{0}-r\right)^{2}}\right] /\left[b \cdot\left(R_{0}-r\right)\right] \\
d^{2} r / d y^{2}=a^{4} /\left[b^{2} \cdot\left(R_{0}-r\right)^{3}\right]
\end{gathered}
$$

Appropriate customizations lead to:

\section{- for contour $\overparen{A B C}$ :}

$\left\{\varphi \in[0 ; \pi] ; r \geq R_{0} ; r=R_{0}+x ; x \in[0 ; a] ; A(\varphi=0) ; B(\varphi=\pi / 2) ; C(\varphi=\pi)\right\}:$ 


$$
\begin{gathered}
R_{1}=\left[\left(b^{2}-a^{2}\right) \cdot\left(r-R_{0}\right)^{2}+a^{4}\right]^{3 / 2} /\left(a^{4} \cdot b\right)=a^{2} \cdot b^{2} /\left(a^{2} \cdot \sin ^{2} \varphi+b^{2} \cdot \cos ^{2} \varphi\right)^{3 / 2}= \\
=\left[\left(b^{2}-a^{2}\right) \cdot x^{2}+a^{4}\right]^{3 / 2} /\left(a^{4} \cdot b\right) \\
R_{2}=r \cdot\left[\left(b^{2}-a^{2}\right) \cdot\left(r-R_{0}\right)^{2}+a^{4}\right]^{1 / 2} /\left[b \cdot\left(r-R_{0}\right)\right]= \\
\left.=\left[R_{0} /|\sin \varphi|\right]+a^{2} /\left(a^{2} \cdot \sin ^{2} \varphi+b^{2} \cdot \cos \right)^{2} \varphi\right)^{1 / 2}= \\
=\left(R_{0}+x\right) \cdot\left[\left(b^{2}-a^{2}\right) \cdot x^{2}+a^{4}\right]^{1 / 2} /(b \cdot x) \\
=\left[b \cdot\left(R_{2} \cdot|\sin \varphi|-R_{0}\right)\right] /\left[\left(b^{2}-a^{2}\right) \cdot\left(R_{2} \cdot|\sin \varphi|-R_{0}\right)^{2}+a^{4}\right]^{1 / 2}= \\
\left.\left.\sin \varphi=\left[b \cdot\left(r-R_{0}\right)\right] /\left[\left(b^{2}-a^{2}\right) \cdot x^{2}+a^{4}\right]^{1 / 2}\right) \cdot\left(r-R_{0}\right)^{2}+a^{4}\right]^{1 / 2}= \\
=\left\{\begin{array}{c}
\cos \varphi=\left\{a \cdot\left[a^{2}-\left(r-R_{0}\right)^{2}\right]\right. \\
\left.\left.\left.=\left(R_{2} \cdot|\sin \varphi|-R_{0}\right)^{2}\right]\right]^{1 / 2}\right\} /\left[\left(b^{2}-a^{2}\right) \cdot\left(R_{2} \cdot|\sin \varphi|-R_{0}\right)^{2}+a^{4}\right]^{1 / 2}= \\
=\left[a \cdot\left(a^{2}-x^{2}\right)^{1 / 2}\right] /\left[\left(b^{2}-a^{2}\right) \cdot x^{2}+a^{4}\right]^{1 / 2}
\end{array}\right.
\end{gathered}
$$

\section{- for contour $\overparen{C D A}$ :}

$$
\begin{gathered}
\left\{\varphi \in[\pi ; 2 \cdot \pi] ; r \leq R_{0} ; x \in[0 ; a] ; C(\varphi=\pi) ; D(\varphi=3 \cdot \pi / 2) ; A(\varphi=2 \cdot \pi)\right\}: \\
R_{1}=\left[a^{4}+\left(b^{2}-a^{2}\right) \cdot\left(R_{0}-r\right)^{2}\right]^{3 / 2} /\left(a^{4} \cdot b\right)=a^{2} \cdot b^{2} /\left(a^{2} \cdot \sin ^{2} \varphi+b^{2} \cdot \cos ^{2} \varphi\right)^{3 / 2}= \\
=\left[a^{4}+\left(b^{2}-a^{2}\right) \cdot x^{2}\right]^{3 / 2} /\left(a^{4} \cdot b\right) \\
R_{2}=r \cdot\left[a^{4}+\left(b^{2}-a^{2}\right) \cdot\left(R_{0}-r\right)^{2}\right]^{1 / 2} /\left[b \cdot\left(R_{0}-r\right)\right]= \\
=\left[R_{0} /|\sin \varphi|\right]-a^{2} /\left(a^{2} \cdot \sin ^{2} \varphi+b^{2} \cdot \cos { }^{2} \varphi\right)^{1 / 2}= \\
=\left(R_{0}-x\right) \cdot\left[a^{4}+\left(b^{2}-a^{2}\right) \cdot x^{2}\right]^{1 / 2} /(b \cdot x) \\
\sin \varphi=\left[b \cdot\left(R_{0}-r\right)\right] /\left[a^{4}+\left(b^{2}-a^{2}\right) \cdot\left(R_{0}-r\right)^{2}\right]^{1 / 2}= \\
=\left[b \cdot\left(R_{0}-R_{2} \cdot|\sin \varphi|\right)\right] /\left[a^{4}+\left(b^{2}-a^{2}\right) \cdot\left(R_{0}-R_{2} \cdot|\sin \varphi|\right)^{2}\right]^{1 / 2}= \\
=b \cdot x /\left[a^{4}+\left(b^{2}-a^{2}\right) \cdot x^{2}\right]^{1 / 2}
\end{gathered}
$$

$$
\cos \varphi=\left\{a \cdot\left[a^{2}-\left(R_{0}-r\right)^{2}\right]^{1 / 2}\right\} /\left[a^{4}+\left(b^{2}-a^{2}\right) \cdot\left(R_{0}-r\right)^{2}\right]^{1 / 2}=
$$




$$
\begin{gathered}
=\left\{a \cdot\left[a^{2}-\left(R_{0}-R_{2} \cdot|\sin \varphi|\right)^{2}\right]^{1 / 2}\right\} /\left[a^{4}+\left(b^{2}-a^{2}\right) \cdot\left(R_{0}-R_{2} \cdot|\sin \varphi|\right)^{2}\right]^{1 / 2}= \\
=\left[a \cdot\left(a^{2}-x^{2}\right)^{1 / 2}\right] /\left[a^{4}+\left(b^{2}-a^{2}\right) \cdot x^{2}\right]^{1 / 2}
\end{gathered}
$$

where $R_{0}$ has the meaning in Figure 1, with equality being noted $x=r-R_{0} \in[0 ; a]$.

Note: For the determination of dimensions $x$, the semi ax $b$ conveniently divided in a positive or negative sense, the respective values being introduced into equality:

$$
x=a \cdot \sqrt{1-y^{2} / b^{2}}
$$

deduced from the equation of the generating ellipse (with center $O_{1}$ - Figure1).

\subsection{Normal unitary forces, meridional and annular}

Under the action of the internal overpressure $p$, the following unit expressions are found for the normal unitary forces $S(p)$ and $T(p)[15]$ :

- for contour $\overparen{A B C}\left(r \geq R_{0} ; r=R_{0}+x ; x \in[0 ; a]\right)$ :

$$
\begin{gathered}
S(p)=\frac{p \cdot\left(r^{2}-R_{0}^{2}\right)}{2 \cdot r \cdot(\sin \varphi)}=\frac{p \cdot\left(r+R_{0}\right)}{2 \cdot b \cdot r} \cdot\left[a^{4}+\left(b^{2}-a^{2}\right) \cdot\left(r-R_{0}\right)^{2}\right]^{1 / 2} \\
T(p)=p \cdot R_{2} \cdot\left[1-\frac{r^{2}-R_{0}^{2}}{2 \cdot R_{1} \cdot r \cdot(\sin \varphi)}\right]=\frac{p}{2 \cdot b} \cdot \frac{a^{4}+2 \cdot r \cdot\left(b^{2}-a^{2}\right) \cdot\left(r-R_{0}\right)}{\left[a^{4}+\left(b^{2}-a^{2}\right) \cdot\left(r-R_{0}\right)^{2}\right]^{1 / 2}}
\end{gathered}
$$

in which the variable $r$, respectively:

- for contour $\overparen{C D A}\left(r \leq R_{0} ; r=R_{0}-x\right)$ :

$$
\begin{gathered}
S(p)=\frac{p \cdot\left(R_{0}^{2}-r^{2}\right)}{2 \cdot r \cdot(\sin \varphi)}=\frac{p \cdot\left(r+R_{0}\right)}{2 \cdot b \cdot r} \cdot\left[a^{4}+\left(b^{2}-a^{2}\right) \cdot\left(R_{0}-r\right)^{2}\right]^{1 / 2} \\
T(p)=p \cdot R_{2} \cdot\left[1-\frac{R_{0}^{2}-r^{2}}{2 \cdot R_{1} \cdot r \cdot(\sin \varphi)}\right]=\frac{p}{2 \cdot b} \cdot \frac{a^{4}+2 \cdot r \cdot\left(b^{2}-a^{2}\right) \cdot\left(R_{0}-r\right)}{\left[a^{4}+\left(b^{2}-a^{2}\right) \cdot\left(R_{0}-r\right)^{2}\right]^{1 / 2}}
\end{gathered}
$$

\subsection{Stress state}

By referring to the relations of calculation of the normal unitary forces, we can deduce the formulas characteristic of the normal meridional and annular stresses - no thermal effect - written in the form:

- For contour $\overparen{A B C}\left(r \geq R_{0} ; r=R_{0}+x ; x \in[0 ; a]\right)$ :

$$
\sigma_{1 d}(p)=\frac{p}{2 \cdot b \cdot \delta} \cdot\left\{\left(1+\frac{R_{0}}{R_{0}+x}\right) \cdot\left[a^{4}+\left(b^{2}-a^{2}\right) \cdot x^{2}\right]^{1 / 2}\right\}
$$




$$
\sigma_{2 d}(p)=\frac{p}{2 \cdot b \cdot \delta} \cdot \frac{a^{4}+2 \cdot\left(R_{0}+x\right) \cdot\left(b^{2}-a^{2}\right) \cdot x}{\left[a^{4}+\left(b^{2}-a^{2}\right) \cdot x^{2}\right]^{1 / 2}}
$$

representing the normal stress on the right side of the ellipse, the sizes $R_{1}$ and $R_{2}$ being able to be replaced with $x$ dependent expressions $(7,8)$.

$$
\begin{aligned}
& \text { - for contour } \overparen{C D A}\left(r \leq R_{0} ; r=R_{0}-|x| ;|x| \in[0 ; a]\right): \\
& \qquad \begin{array}{c}
\sigma_{1 s}(p)=\frac{p}{2 \cdot b \cdot \delta} \cdot\left(1+\frac{R_{0}}{R_{0}-x}\right) \cdot\left[a^{4}+\left(b^{2}-a^{2}\right) \cdot x^{2}\right]^{1 / 2} \\
\sigma_{2 s}(p)=\frac{p}{2 \cdot b \cdot \delta} \cdot \frac{a^{4}+2 \cdot\left(R_{0}-x\right) \cdot\left(b^{2}-a^{2}\right) \cdot x}{\left[a^{4}+\left(b^{2}-a^{2}\right) \cdot x^{2}\right]^{1 / 2}}
\end{array}
\end{aligned}
$$

representing the normal stress on the left side of the ellipse, the sizes $R_{1}$ and $R_{2}$ being able to be replaced with $x$ dependent expressions $(7,8)$.

Note: The following customizations are deduced from the comparison of previous expressions for normal stress:

- in points $\mathrm{A}$ and $\mathrm{C}\left(x=0 ; r=R_{0}\right.$ - Figure 1):

$$
\begin{gathered}
\sigma_{1 d}(p)=\sigma_{1 s}(p)=p \cdot a^{2} /(b \cdot \delta) ; \quad \sigma_{2 d}(p)=\sigma_{2 s}(p)=p \cdot a^{2} /(2 \cdot b \cdot \delta) \\
{\left[\sigma_{1 d}(p) ; \sigma_{1 s}(p)\right] /\left[\sigma_{2 d}(p) ; \sigma_{2 s}(p)\right]=2}
\end{gathered}
$$

- in point $\mathbf{B}\left(x=a ; r=R_{0}+a\right.$ - Figure 1$)$ :

$$
\begin{gathered}
\sigma_{1 d}(p)=\frac{p \cdot a}{2 \cdot \delta} \cdot\left(1+\frac{R_{0}}{R_{0}+a}\right) \\
\sigma_{2 d}(p)=\frac{p}{2 \cdot b^{2} \cdot \delta} \cdot\left[a^{3}+2 \cdot\left(R_{0}+a\right) \cdot\left(b^{2}-a^{2}\right)\right]
\end{gathered}
$$

- in point $\mathbf{D}\left(|x|=a ; r=R_{0}-a\right.$ - Figure 1):

$$
\begin{gathered}
\sigma_{1 d}(p)=\frac{p \cdot a}{2 \cdot \delta} \cdot\left(1+\frac{R_{0}}{R_{0}-a}\right) \\
\sigma_{2 d}(p)=\frac{p}{2 \cdot b^{2} \cdot \delta} \cdot\left[a^{3}+2 \cdot\left(R_{0}-a\right) \cdot\left(b^{2}-a^{2}\right)\right]
\end{gathered}
$$

\subsection{Deformation state}

The specific linear deformations produced in the case of such a structure, in case of the internal overpressure, are in the form [16]: 
- for contour $\overparen{A B C}\left(r \geq R_{0} ; r=R_{0}+x ; x \in[0 ; a]\right)$ :

$$
\begin{gathered}
\varepsilon_{1 d}(p)=\frac{p}{2 \cdot E \cdot b \cdot \delta} \cdot\left[\begin{array}{c}
\left(1+\frac{R_{0}}{R_{0}+x}\right) \cdot \sqrt{a^{4}+\left(b^{2}-a^{2}\right) \cdot x^{2}}- \\
-v \cdot \frac{a^{4}+2 \cdot\left(R_{0}+x\right) \cdot\left(b^{2}-a^{2}\right) \cdot x}{\sqrt{a^{4}+\left(b^{2}-a^{2}\right) \cdot x^{2}}}
\end{array}\right] \\
\varepsilon_{2 d}(p)=\frac{p}{2 \cdot E \cdot b \cdot \delta} \cdot\left[\begin{array}{c}
\frac{a^{4}+2 \cdot\left(R_{0}+x\right) \cdot\left(b^{2}-a^{2}\right) \cdot x}{\sqrt{a^{4}+\left(b^{2}-a^{2}\right) \cdot x^{2}}}- \\
-v \cdot\left(1+\frac{R_{0}}{R_{0}+x}\right) \cdot \sqrt{a^{4}+\left(b^{2}-a^{2}\right) \cdot x^{2}}
\end{array}\right]
\end{gathered}
$$

respectively:

- for contour $\overparen{C D A}\left(r \leq R_{0} ; r=R_{0}-|x| ;|x| \in[0 ; a]\right)$ :

$$
\begin{gathered}
\varepsilon_{1 s}(p)=\frac{p}{2 \cdot E \cdot b \cdot \delta} \cdot\left[\begin{array}{c}
\left(1+\frac{R_{0}}{R_{0}-x}\right) \cdot \sqrt{a^{4}+\left(b^{2}-a^{2}\right) \cdot x^{2}}- \\
-v \cdot \frac{a^{4}+2 \cdot\left(R_{0}-x\right) \cdot\left(b^{2}-a^{2}\right) \cdot x}{\sqrt{a^{4}+\left(b^{2}-a^{2}\right) \cdot x^{2}}}
\end{array}\right] \\
\varepsilon_{2 s}(p)=\frac{p}{2 \cdot E \cdot b \cdot \delta} \cdot\left[\begin{array}{c}
\frac{a^{4}+2 \cdot\left(R_{0}-x\right) \cdot\left(b^{2}-a^{2}\right) \cdot x}{\sqrt{a^{4}+\left(b^{2}-a^{2}\right) \cdot x^{2}}}- \\
-v \cdot\left(1+\frac{R_{0}}{R_{0}-x}\right) \cdot \sqrt{a^{4}+\left(b^{2}-a^{2}\right) \cdot x^{2}}
\end{array}\right]
\end{gathered}
$$

condition $a^{4}+\left(b^{2}-a^{2}\right) \cdot x^{2}>0$ being accomplished for $|x| \in[0 ; a]$.

Equations (7) - (15) for the main curvature rays and (29) - (32) for specific linear deformations can be used in the evaluation of the displacements of the points of the meridian of the shell $u(p)$ and $w(p)$ respectively the radial displacement $\Delta r(p)$ written in the form [16]:

- for contour $\overparen{A B C}\left(r \geq R_{0} ; r=R_{0}+x ; x \in[0 ; a]\right)$ :

$$
u_{d}(p)=\frac{b \cdot x}{\sqrt{a^{4}+\left(b^{2}-a^{2}\right) \cdot x^{2}}} \cdot I_{d}
$$




$$
\begin{gathered}
w_{d}(p)=\frac{a \cdot \sqrt{a^{2}-x^{2}}}{\sqrt{a^{4}+\left(b^{2}-a^{2}\right) \cdot x^{2}}} \cdot I_{d}-\frac{p \cdot\left(R_{0}+x\right)}{2 \cdot E \cdot \delta \cdot b^{2} \cdot x} \cdot \\
\cdot\left\{a^{4}+2 \cdot\left(R_{0}+x\right) \cdot\left(b^{2}-a^{2}\right) \cdot x-v \cdot \frac{2 \cdot R_{0}+x}{R_{0}+x} \cdot\left[a^{4}+\left(b^{2}-a^{2}\right) \cdot x^{2}\right]\right\} \\
\Delta r_{d}(p)=\frac{p \cdot\left(R_{0}+x\right)}{2 \cdot E \cdot b \cdot \delta \cdot \sqrt{a^{4}+\left(b^{2}-a^{2}\right) \cdot x^{2}}} \cdot\left\{\begin{array}{c}
a^{4}+2 \cdot\left(R_{0}+x\right) \cdot\left(b^{2}-a^{2}\right) \cdot x- \\
-v \cdot \frac{2 \cdot R_{0}+x}{R_{0}+x} \cdot\left[a^{4}+\left(b^{2}-a^{2}\right) \cdot x^{2}\right]
\end{array}\right\}
\end{gathered}
$$

- for contour $\overparen{C D A}\left(r \leq R_{0} ; r=R_{0}-|x| ;|x| \in[0 ; a]\right)$ :

$$
\begin{gathered}
u_{s}(p)=\frac{b \cdot x}{\sqrt{a^{4}+\left(b^{2}-a^{2}\right) \cdot x^{2}}} \cdot I_{s} \\
w_{s}(p)=\frac{a \cdot \sqrt{a^{2}-x^{2}}}{\sqrt{a^{4}+\left(b^{2}-a^{2}\right) \cdot x^{2}}} \cdot I_{s}-\frac{p \cdot\left(R_{0}-x\right)}{2 \cdot E \cdot \delta \cdot b^{2} \cdot x} \cdot \\
\cdot\left\{a^{4}+2 \cdot\left(R_{0}-x\right) \cdot\left(b^{2}-a^{2}\right) \cdot x-v \cdot \frac{2 \cdot R_{0}-x}{R_{0}-x} \cdot\left[a^{4}+\left(b^{2}-a^{2}\right) \cdot x^{2}\right]\right\} \\
\Delta r_{s}(p)=\frac{p \cdot\left(R_{0}-x\right)}{2 \cdot E \cdot b \cdot \delta \cdot \sqrt{a^{4}+\left(b^{2}-a^{2}\right) \cdot x^{2}}} \cdot\left\{\begin{array}{c}
a^{4}+2 \cdot\left(R_{0}-x\right) \cdot\left(b^{2}-a^{2}\right) \cdot x- \\
\left.-v \cdot \frac{2 \cdot R_{0}-x}{R_{0}-x} \cdot\left[a^{4}+\left(b^{2}-a^{2}\right) \cdot x^{2}\right]\right\}
\end{array}\right.
\end{gathered}
$$

in which equality is considered:

$$
I_{d}=\frac{p}{2 \cdot E \cdot a \cdot b^{2} \cdot \delta} \cdot\left\{\begin{array}{c}
I_{1}+R_{0} \cdot I_{2 d}-v \cdot a^{4} \cdot I_{3}-2 \cdot v \cdot R_{0} \cdot\left(b^{2}-a^{2}\right) \cdot I_{4}- \\
-2 \cdot v \cdot\left(b^{2}-a^{2}\right) \cdot I_{5}-a^{8} \cdot R_{0} \cdot I_{6}- \\
-a^{4} \cdot\left[a^{4}+2 \cdot R_{0}^{2} \cdot\left(b^{2}-a^{2}\right)\right] \cdot I_{7}- \\
-4 \cdot R_{0} \cdot a^{4} \cdot\left(b^{2}-a^{2}\right) \cdot I_{8}-2 \cdot a^{4} \cdot\left(b^{2}-a^{2}\right) \cdot I_{9}+ \\
+2 \cdot v \cdot R_{0} \cdot a^{4} \cdot I_{10}+v \cdot a^{4} \cdot I_{11}
\end{array}\right\}\left\{\begin{array}{c}
I_{1}+R_{0} \cdot I_{2 s}-v \cdot a^{4} \cdot I_{3}-2 \cdot v \cdot R_{0} \cdot\left(b^{2}-a^{2}\right) \cdot I_{4}- \\
-2 \cdot v \cdot\left(b^{2}-a^{2}\right) \cdot I_{5}-a^{8} \cdot R_{0} \cdot I_{6}+ \\
+a^{4} \cdot\left[a^{4}+2 \cdot R_{0}^{2} \cdot\left(b^{2}-a^{2}\right)\right] \cdot I_{7}+ \\
+2 \cdot a^{4} \cdot\left(b^{2}-a^{2}\right) \cdot I_{9}+2 \cdot v \cdot R_{0} \cdot a^{4} \cdot I_{10}-v \cdot a^{4} \cdot I_{11}
\end{array}\right\}
$$


respectively the expressions of indefinite integrals:

$$
\begin{aligned}
& I_{1}=\int_{x} \frac{\left[a^{4}+\left(b^{2}-a^{2}\right) \cdot x^{2}\right]^{3 / 2}}{x \cdot\left(a^{2}-x^{2}\right)^{1 / 2}} \cdot d x \\
& I_{2 d}=\int_{x} \frac{\left[a^{4}+\left(b^{2}-a^{2}\right) \cdot x^{2}\right]^{3 / 2}}{x \cdot\left(R_{0}+x\right) \cdot\left(a^{2}-x^{2}\right)^{1 / 2}} \cdot d x ; I_{2 s}=\int_{x} \frac{\left[a^{4}+\left(b^{2}-a^{2}\right) \cdot x^{2}\right]^{3 / 2}}{x \cdot\left(R_{0}-x\right) \cdot\left(a^{2}-x^{2}\right)^{1 / 2}} \cdot d x \\
& I_{3}=\int_{x} \frac{\left[a^{4}+\left(b^{2}-a^{2}\right) \cdot x^{2}\right]^{1 / 2}}{x \cdot\left(a^{2}-x^{2}\right)^{1 / 2}} \cdot d x ; \quad I_{4}=\int_{x} \frac{\left[a^{4}+\left(b^{2}-a^{2}\right) \cdot x^{2}\right]^{1 / 2}}{\left(a^{2}-x^{2}\right)^{1 / 2}} \cdot d x \\
& I_{5}=\int_{x} \frac{x \cdot\left[a^{4}+\left(b^{2}-a^{2}\right) \cdot x^{2}\right]^{1 / 2}}{\left(a^{2}-x^{2}\right)^{1 / 2}} \cdot d x \\
& I_{6}=\int_{x} \frac{d x}{x^{2} \cdot\left(a^{2}-x^{2}\right)^{1 / 2} \cdot\left[a^{4}+\left(b^{2}-a^{2}\right) \cdot x^{2}\right]^{1 / 2}} \\
& I_{7}=\int_{x} \frac{d x}{x \cdot\left(a^{2}-x^{2}\right)^{1 / 2} \cdot\left[a^{4}+\left(b^{2}-a^{2}\right) \cdot x^{2}\right]^{1 / 2}} \\
& I_{8}=\int_{x} \frac{d x}{\left(a^{2}-x^{2}\right)^{1 / 2} \cdot\left[a^{4}+\left(b^{2}-a^{2}\right) \cdot x^{2}\right]^{1 / 2}} \\
& I_{9}=\int_{x} \frac{x}{\left(a^{2}-x^{2}\right)^{1 / 2} \cdot\left[a^{4}+\left(b^{2}-a^{2}\right) \cdot x^{2}\right]^{1 / 2}} \cdot d x \\
& I_{10}=\int_{x} \frac{\left[a^{4}+\left(b^{2}-a^{2}\right) \cdot x^{2}\right]^{1 / 2}}{x^{2} \cdot\left(a^{2}-x^{2}\right)^{1 / 2}} \cdot d x ; \quad I_{11}=\int_{x} \frac{\left[a^{4}+\left(b^{2}-a^{2}\right) \cdot x^{2}\right]^{1 / 2}}{x \cdot\left(a^{2}-x^{2}\right)^{1 / 2}} \cdot d x
\end{aligned}
$$

The correspondence that was considered in the calculating the displacement of the points of the meridian of the shell $u(p)$ and $w(p)$ and the radial displacement $\Delta r(p)$ :

$$
d \varphi=\frac{a^{3} \cdot b}{\left[a^{4}+\left(b^{2}-a^{2}\right) \cdot x^{2}\right] \cdot\left(a^{2}-x^{2}\right)^{1 / 2}} \cdot d x .
$$

Note: In the above relationships, the established condition is $x \neq \pm a$.

The expressions for radial linear displacement of the points of the parallel circles, respectively the rotation of the meridian, considering the equalities (16) can also be determined: 


$$
\begin{aligned}
& \Delta r(p)=\left\{u(p) \cdot\left[a \cdot\left(a^{2}-x^{2}\right)^{1 / 2}\right]-w(p) \cdot b \cdot x\right\} \cdot \frac{1}{\left[a^{4}+\left(b^{2}-a^{2}\right) \cdot x^{2}\right]^{1 / 2}} \\
& \theta(p)=\frac{a^{4} \cdot b}{\left[a^{4}+\left(b^{2}-a^{2}\right) \cdot x^{2}\right]^{3 / 2}} \cdot\left\{+\frac{u(p)+}{b \cdot x^{3}}+\frac{\left[a^{4}+\left(b^{2}-a^{2}\right) \cdot x^{2}\right] \cdot\left(a^{2}-x^{2}\right)^{1 / 2}}{d w(p)} \frac{d w}{d x}\right\}
\end{aligned}
$$

for the right and the left side, respectively, of the ellipsoidal cross-section of the toroidal shell.

Note: Another way of positioning the cross-section of the ellipsoidal shape of the toroidal shell is shown in Figure 2.

The paper [8] identifies appropriate relationships that can assess critical overpressure, written as:

- for the cross-section case, with the large horizontal axis (Figure 1):

$$
\left(p_{c r}\right)_{1}=\frac{0,358 \cdot E \cdot \delta^{2}}{\left\{2 \cdot\left[\left(R_{0} / a\right)+1\right] \cdot\left[\left(b^{2} / a^{2}\right)-1\right]+1\right\} \cdot a^{2}}
$$

- for the case of the cross section with the minor axis horizontal (Figure 2):

$$
\left(p_{c r}\right)_{1}=\frac{0,358 \cdot E \cdot \delta^{2}}{\left\{2 \cdot\left[\left(R_{0} / a\right)-1\right] \cdot\left[\left(b^{2} / a^{2}\right)-1\right]-1\right\} \cdot a^{2}}
$$

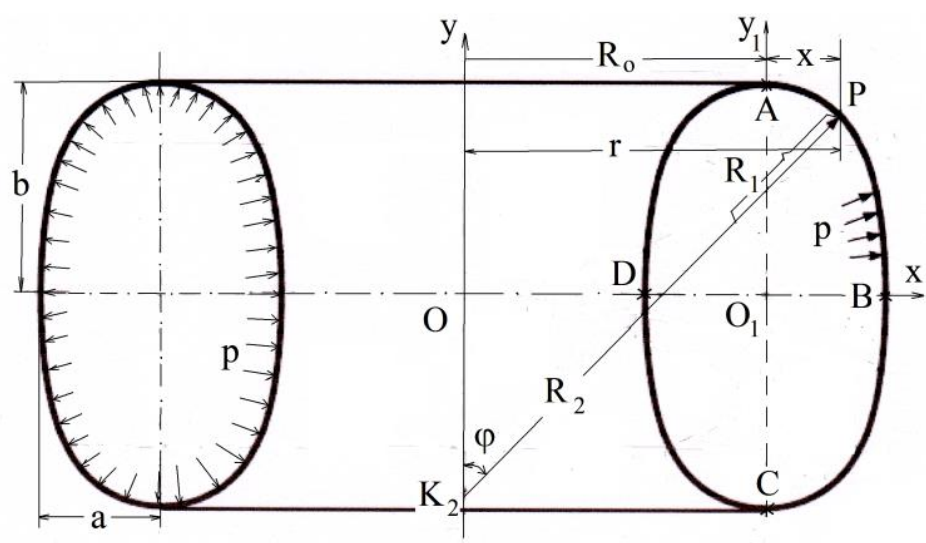

Fig. 2. Toroidal shell with elliptical cross-section with small horizontal axis $(a<b)$.

\section{Abbreviations:}

$a, b-$ semi axes of the medial ellipse of the cross section of the torus; $p-$ working environment pressure; $p_{c r}-$ critical pressure; $r-$ radius of current points $P ; u, w-$ the displacements of the meridian points along the main radii of curvature; $x-$ current dimension; $\delta-$ the thickness of the shell wall; $\varepsilon_{1}, \varepsilon_{2}-$ specific linear deformations; angle to center of points $P ; \quad v-$ the transverse contraction coefficient of the material; $\theta-$ rotating the meridian; $\sigma_{1}, \sigma_{2}-$ normal meridional stress; $\Delta r-$ variation of current radius $r ; E-$ the modulus of longitudinal elasticity of the material; $P-$ the position of the current points 
on the medial ellipse circumference of shell; $S, T-$ meridional and annular unitary force developed by the inner working pressure; $R_{0}$ - the radius of the position of the ellipse axis parallel to the axis of symmetry of the toroidal shell; $R_{1}, R_{2}-$ main radii of curvature; $O x, O y-$ the chosen reference system axe.

\section{CONCLUSIONS}

The analytical study analyzes stress and deformation states in the configuration of toroidal cross-sections of elliptical shape with two positions that can be found in industrial practice. In this regard, the two possible cases are to be considered, namely when the ellipse's large axis is in the horizontal plane, respectively in the vertical plane. The internal pressure of a working environment and its temperature effect are used as external loads. The two effects may overlap, considering the state of stress in the elastic domain of the material of the given structure.

\section{REFERENCES}

[1] Kantorovici, B.Z., Osnovî rasceta himiceskâh maşin i apparatov (limba rusă), Maşghiz, Moskva, 1952.

[2] Ponomariov, D.S., Calculul de rezistenţă în construcţia de maşini (traducere din limba rusă), vol. 2, Editura Tehnică, București, 1963.

[3] Domaşnev, D.A., Utilaje pentru indsutria chimică - calcul şi proiectare (traducere din limba rusă), Editura Tehnică, Bucureşti, 1963.

[4] Gill, S.S., The stress analysis of pressure vessels and pressure vessel components, vol. 1, Pergammon Press Ltd., New York, 1970.

[5] Renert, M., Calculul şi construcţia utilajului chimic, vol. 1, Editura Didactică şi Pedagogică, București, 1971.

[6] Jinescu, V.V., Calculul şi construcţia utilajului cjimic, petrochimic şi de rafinării, vol. 1, Editura didactică şi Pedagogică, Bucureşti, 1983.

[7] Jinescu, V.V., Utilaje pentru industrii de proces, vol. 1, Editura Tehnică, Bucureşti, 1983.

[8] Lizin, V.T., Piatkin, A.V., Proektironanie tonkostennâh konstrukții, Maşinostroenie. Moskva, 1985.

[9] Gallethy, G.D., Blechut, J.M., Torisferical shells under internal pressure - failure due to asymmetric plastic buckling or axisymmetric yielding, Proc. Instn. Mech. Engrs., 199, nr. C 3, 1985. p. 225 - 238.

[10] Blackler, J.M., Stability of silos and tanks under internal and external pressure, Thesis, The University of Sydney, Oct. 1986.

[11] Vu, Tr.V., Blachut, J., Plastic instability pressure of toroidal shells, Journal of Pressure Vessel Technology, $\begin{array}{lllllll}\text { Transactions of the ASME, vol. } 138, & \text { no. } & 2, & 2015 .\end{array}$ (http://pressurevesseltech.asmedigitalcollection.asme.org/article.aspx?articleid=1473498, on line at 11.07.18).

[12] Vu, Tr.V., Optimum shape of constant stress toroidal shells, Journal of Pressure Vessel Technology, $\begin{array}{llllll}\text { Transactions of the } & \text { ASME, } & \text { vol. }\end{array}$ (https://www.researchgate.net/publication/257984913_Optimum_Shape_Of_Constant_Stress_Toroidal_Shells on line at 11.07.18).

[13] Vu, Tr.V., Minimum weight design for toroidal shells with strengthening component, Journal of Pressure Vessel Technology, Transactions of the ASME, vol. 138, no. 2, 2016. (http://pressurevesseltech.asmedigitalcollection.asme.org/article.aspx?articleid=2499940 - on line at 11.07.18).

[14] Iatan, I.R., Nicolau, L., Evaluarea influenței racordării între virolele tronconice şi cilindrice asupra stării de tensiuni, Buletinul Institutului Politehnic Bucureşti, vol. 50, 1988, p. 57 - 64.

[15] Avdonin, S.A., Prikladnâe metodî rasceta obolociek i tonkostennâh konstrukţii, Izd. "Maşinostroenie", Moskva, 1969.

[16] Iatan, I.R., Elemente de teoria liniară a elasticităţii corpurilor de rotaţie (manuscris), Bucureşti, 2019. 